\title{
LA CAPILLA MUSICAL DE DON CRISTÓBAL DE ROJAS EN LA CATEDRAL DE CÓRDOBA
}

\author{
por María Teresa Dabrio GonZález
}

\begin{abstract}
El estudio de la documentación existente en la catedral de Córdoba relativa a la constitución de una capilla musical, así como el funcionamiento de ella, es el asunto de este trabajo. Aparece la figura de Don Cristóbal de Rojas, obispo de Córdoba y más tarde arzobispo de Sevilla, como fundador de este grupo musical. Asimismo, la familia de músicos apellidados Medrano se presentan como principales figuras de esta capilla musical.
\end{abstract}

En la Introducción que Antonio Martín Moreno escribiera en 1985 para su Historia de la Música Andaluza, se aludía a todo lo que aún se desconoce en el panorama musical andaluz, en el que todavía quedan amplias parcelas sin explorar, no sólo en lo que a la propia música se refiere, sino también al proceso histórico de la misma, esto es, al conocimiento de las personas y circunstancias que hicieron posible la existencia de una de las páginas más brillantes de la historia musical española. Con este trabajo queremos contribuir al mejor conocimiento de este riquísimo patrimonio cultural, dando a conocer la formación y primeros componentes que tuvo la Capilla Musical de la Catedral de Córdoba a comedios del siglo XVI ${ }^{1}$.

1. En el presente trabajo -que forma parte de un estudio más extenso en el que se analizará la capilla completacentraremos nuestra atención en la creación de esta Capilla, sus estatutos y los ministriles que la compusieron. Para ello hemos tomado como base documental principal las Actas Capitulares de la Catedral de Córdoba correspondientes al siglo XVI. Agradecemos al canónigo archivero de la misma, D. Manuel Nieto Cumplido, las facilidades que nos ha dado para poder llevarlo a cabo. 
La idea de una Capilla Musical tal como hoy la entendemos está, en el caso de Córdoba, indefectiblemente unida a la llegada a esta sede del obispo D. Cristóbal de Rojas y Sandoval en la primavera de 1563. Cierto es que con anterioridad a esta fecha la Catedral contó con músicos a su servicio, pero éstos no se ajustaban a una reglamentación ordenada y precisa como sucederá a partir de la fecha citada ${ }^{2}$.

Hombre de ilustre linaje, el nuevo prelado era hijo del Marqués de Denia y había nacido en 1502; graduado en Teología por Alcalá de Henares, fue capellán del emperador Carlos y posteriormente titular de las sedes de Oviedo y Badajoz, siendo uno de los prelados españoles presentes en las sesiones del Concilio de Trento ${ }^{3}$. Permaneció en Córdoba hasta 1571 en que fue promovido al Arzobispado de Sevilla; murió en 1581 en la villa de Cigales (Valladolid) ${ }^{4}$.

Gómez Bravo nos ha dejado una semblanza breve, pero reveladora, del talante del obispo: “... en su trato fue muy llano, en la comida templado y en el vestido limpio sin artificio y preciosidad... tuvo gran opinión de recto, limosnero, honesto y compasivo". Pero, curiosamente casi nada se dice de su interés por las obras artísticas, si exceptuamos la breve alusión que se hace a la subida de los excusados 5 . Porque, en efecto, esta subida de impuestos respondía a una finalidad concreta: potenciar la música. Como ya se ha señalado, hasta entonces la música no había jugado un papel brillante dentro del ceremonial litúrgico catedralicio y ello no parecía haber preocupado en demasía ni al Cabildo ni a los anteriores prelados.

Ahora las cosas se miran desde una perspectiva diferente: D. Cristóbal de Rojas -como se ha dicho- procedía de noble cuna, había sido capellán imperial y había asistido a Trento, tres aspectos que justifican plenamente su interés por la música, y su deseo de tener una capilla de categoría que le recordase su vida en la Corte ${ }^{6}$. Por eso se comprende también su extrañeza ante la circunstancia de que una catedral como Córdoba, siendo como era "su antigüedad y grandeza tanta", no dispusiera del suficiente presupuesto para afrontar simultáneamente

2. Las Actas Capitulares anteriores a $\mathbf{1 5 6 3}$ mencionan de modo esporádico la presencia de ministriles, organistas y mozos de coro, pero no dejan traslucir una preocupación especial por parte del Cabildo en lo referente a sus obligaciones.

3. GÓMEZ BRAVO, Juan: Catálogo de los obispos de Córdoba. T. II, Córdoba, 1778, pp. 469-470.

4. GÓMEZ BRAVO, J.: Op. cit., pp. 483-484. Por su parte, Arana de Varflora sostiene que el óbito se produjo en 1580. Cfr. ARANA DE VARFLORA, Fermín: Compendio histórico-descriptivo de la muy noble y muy leal ciudad de Sevilla, metrópoli de Andalucía. Sevilla, 1766. Reedición, Valencia, 1978, p. 114.

5. GÓMEZ BRAVO, J.: Op. cit., pp. 483 y 470. Sin embargo Ramírez de Arellano señala su relación con las obras del crucero catedralicio. Véase RAMÍREZ DE ARELLANO, T.: Paseos por Córdoba o sean apuntes para su historia. Córdoba, 1976. 3." edición, p. 586.

6. Es probable que el obispo conociese la Capilla Musical de Roma, muy afamada por entonces, y en la que con frecuencia había músicos españoles. Véase al respecto SALAZAR, Adolfo: La música en Cervames y otros ensayos. Madrid, 1961, pp. 295-296. 
los gastos de fábrica y los sueldos de cantores y músicos, siendo este último aspecto de gran importancia para el obispo, quien consideraba su carencia causa de una "gran disminución del culto divino" ?.

Su reacción no se hace esperar; el 21 de abril de 1563 -antes de cumplirse los dos meses de su llegada- se reúne con el Cabildo catedralicio para proponer el incremento de los excusados que recibía el templo, destinándose el dinero así obtenido a sufragar los gastos relacionados con la música; en el caso de que ésta desapareciera por cualquier circunstancia, automáticamente dejaría de cobrarse el citado aumento, cuya cantidad se apreciaba en 85 cahíces y cuatro fanegas de pan terciado y 362.532 maravedíes $^{8}$.

La actitud del prelado, lejos de ser tenida como un hecho aislado y acaso raro, ha de verse enmarcada dentro de toda una corriente de interés por la música sagrada que se materializa en estos años y que da como fruto la aparición de otras capillas musicales en diferentes puntos del país. En 1553 había quedado fijada de modo definitivo la Capilla Musical hispalense y un año después, en 1554 tras algunas dificultades, se constituyó la de Burgos. Valencia la tuvo en 1560 y en 1567 la Catedral de Palencia ${ }^{9}$. Y en el mismo año en que se crea la que comentamos adquiere también carácter permanente la Capilla de la Catedral de Granada ${ }^{10}$.

\section{Los Estatutos}

En líneas generales, las condiciones establécidas por el prelado y el cabildo en los "Estatutos de la Música" para la catedral cordobesa son prácticamente las mismas que regían en otras catedrales. Samuel Rubio ha señalado cómo desde el medievo se toma por modelo a la capilla de música del Papado; es posible que esta imitación llegase hasta el punto de que fuesen sus estatutos los que marcaran la pauta de las obligaciones y deberes que habrían de exigírsele a sus componentes ${ }^{11}$.

7. Archivo de la Catedral de Córdoba (en adelante A.C.C.), Actas Capitulares 1562-1564. Libro 18, fol. 85ํ․

8. A.C.C. Actas Capitulares 1562-64. Libro 18, fols. 85v-89. Como el dinero que se recogería con el nuevo impuesto superaba el valor de los salarios que se pensaban establecer, se acuerda que libremente el Cabildo y el Obispo puedan dar gratificaciones a los músicos y cantores cuando se hicieran acreedores de ello.

9. Tanto en Sevilla como en Burgos se había intentado ya desde la década anterior la creación de una plantilla estable de músicos, pero habían surgido problemas de índole diversa que no lo permitieron. RUBIO, Samuel: Historia de la Música española. Desde el ars nova a I600. Madrid, 1983, pp. 43-44.

10. MARTÍN MORENO, A.: Historia de la música andaluza. Biblioteca de Cultura Andaluza. Granada, 1985, p. 153.

11. RUBIO, S.: Historia de la música... pp. 18-19. 
La existencia de una normativa común podría explicar la gran semejanza que se observa entre estos estatutos, si bien también cabe en lo posible que aquellos que fueron redactados en fechas más tempranas -caso de los de Burgos, que se fechan en 1538- hubieran dado el modelo para todos los demás ${ }^{12}$.

Estas disposiciones contemplaban tanto las distintas plazas que querían crearse y sus correspondientes emolumentos cuanto la serie de normas y obligaciones que todos estos profesionales debían acatar si conseguían el puesto. Estas obligaciones incumbían por igual desde el maestro de capilla, el más alto del escalafón, hasta el último de los ministriles. De acuerdo con tales normas, redactadas el 21 de junio de 1563, todos los componentes de la Capilla Musical debían estar presentes en las misas dominicales, en las fiestas solemnes y en las procesiones ${ }^{13}$. Además de esto, se hace constar de manera expresa que habrían de asistir “... a la misa en los sábados que se rezare de Nuestra Señora, y a la Salve en los sábados de la Cuaresma que se dicen en el Coro" ${ }^{14}$.

Lógicamente el mayor número de normas estaba dirigido al maestro de capilla, pues en éste recaía el papel directivo de todo el conjunto. Tanto éste como el maestro organista podían ser sancionados con la pérdida de parte de su salario. Por lo que atañe a los ministriles hemos de señalar que también sus infracciones estaban penalizadas con un real de multa, pero podían además recibir otras sanciones más severas en el caso de que sus fallos fuesen continuos y reiterados, pudiéndose incluso llegar al despido. Sus obligaciones incluían "tañer en el coro a misa y a primera y segundas vísperas, y en las procesiones generales donde el Cabildo fuere y en los maitines de Navidad"; en general todo el grupo tenía obligación de actuar en cualquier ceremonia en la que participase el Cabildo ${ }^{15}$.

El paso siguiente fue establecer el número de componentes que había de integrar la capilla, tanto en lo instrumental cuanto en voces. Serían los siguientes: maestro de capilla, organista, dos muchachos de coro, cuatro cantores y cuatro ministriles. Para cada uno de ellos se fijó el correspondiente salario, de acuerdo con su categoría: El Maestro de Capilla recibiría anualmente 50.000 maravedíes y tres cahíces de trigo. El salario de los cantores presentaba determinadas variantes; así, mientras la Voz Tiple cobraba al año 50.000 maravedíes, las de Contralto y Contrabajo percibían 45.000 maravedíes, siendo la Voz Tenor la de menor valía, ya que su sueldo anual quedó fijado en 34.000 maravedíes. Sí era igual la parte de trigo, estipulada en dos cahíces de trigo al año para cada uno de ellos.

12. Ya Samuel Rubio se hace eco de esta semejanza, analizando detalladamente los de la Catedral de León, de 1548; muchos de los aspectos tratados en ellos los encontramos también en los de la catedral cordobesa. Cfr. op. cit., pp. 19-20.

13. Obligaciones casi idénticas se recogen en los estatutos de otras catedrales. Cfr. RUBIO, S.: Historia.... p. 46.

14. A.C.C. Actas Capitulares 1562-64. Libro 18, fol. 89v.

15. A.C.C. Actas Capitulares 1562-64. Libro 18, fols. $89 \mathrm{v}-90 \mathrm{v}$. 
En cuanto a los cuatro ministriles, quedó establecido que se les abonaría un sueldo conjunto de 75.000 maravedíes y diez cahíces de trigo ${ }^{16}$.

Para la provisión de todas estas plazas se acordó la convocatoria de un concurso público, designándose al tiempo a los canónigos que habrían de ocuparse de los trámites necesarios, entre los cuales figuraba la publicidad del mismo, pues se les encomienda que "hagan afijar los dichos editos (sic) a las puertas de las iglesias catedrales de Sevilla, Granada, Toledo y Jaén y de otras comarcanas si pareciere...". Parte del Cabildo propuso que viniese como examinador Rodrigo de Ceballos, que por entonces desempeñaba las funciones de Maestro de Capilla de la Catedral de Granada, pero la idea levantó gran polémica, en razón sobre todo de los gastos que ello originaría a la Mesa Capitular ${ }^{17}$. Después de establecer los pertinentes plazos y el modo de elección de los candidatos, se acuerda también la dotación de la plaza de sochantre, cargo que se revelaba a todas luces "tan necesario en todos los coros de las Iglesias catedrales, que sin él no se podría pasar sin desórdenes en las entonaciones y en todo el canto de él..."; se fijó para esto un estipendio anual de 20.000 maravedíes y tres cahíces de trigo, pagaderos según la norma al uso, en los tres tercios del año ${ }^{18}$.

Los meses siguientes fueron de una febril actividad: se publicaron los correspondientes edictos, iniciándose los exámenes en la segunda quincena del mes de junio. Estos se suceden con rapidez y prácticamente a finales de julio estaban ya todas las plazas cubiertas.

\section{La Capilla de Ministriles}

Genéricamente se utiliza el término de "ministriles" para designar a los instrumentistas de viento que trabajaban de manera estable al servicio de una catedral, y que tañían básicamente chirimías, bajones, flautas, cornetas y sacabuches ${ }^{19}$.

En opinión de Carmen Gómez Muntané, el uso del término ministril con connotaciones musicales hay que remontarlo a la Francia del siglo XIII, generalizándose su empleo con rapidez. Al principio estos músicos podían cantar y tañer de modo indistinto, pero paulatinamente fueron especializándose exclusivamente en el manejo instrumental, si bien podían dominar más de un instrumento; sabe-

\footnotetext{
16. Es habitual en la época que se fije en especie una parte del salario, ya en trigo, ya en gallinas. E] cahíz de trigo en Castilla valia 12 fanegas, esto es, aproximadamente unos 660 litros de cereal.

17. A.C.C. Actas Capitulares 1562-64. Libro 18, fols. 112 y v. Con anterioridad a esta fecha Ceballos había desempeñado esta labor en Córdoba y es posible que en relación con eso se halle la verdadera razón de la negativa de un sector del Cabildo. Véase RUBIO, S.: Historia... p. 160. MARTÍN MORENO, A.: Historia... p. 154.

18. A.C.C. Actas Capitulares 1562-64. Libro 18, fols. 89v-90v.

19. RUBIO, S.: Historia... p. 43.
} 
mos que ambos Medrano tocaban, además de la chirimía, la corneta, y el Joven también el bajón ${ }^{20}$. Su principal función estribaba en doblar o suplir a las voces, de ahí que también estuvieran clasificados en tenores, contraltos y contrabajos ${ }^{21}$.

Por lo que se refiere a la estructura formal de estos instrumentos, pocos son los datos que se conocen, tanto por la escasez de piezas originales conservadas cuanto por los exiguos datos teóricos que nos han llegado acerca de su construcción ${ }^{22}$. No obstante, hay otros elementos que pueden ayudar en este empeño: las referencias documentales y las representaciones plásticas de la época. Ambos aspectos vienen a confirmar la importancia que los hombres del XVI concedieron a la Música, sobre todo a la instrumental, que por entonces pugna por desprenderse de la tutela de la voz a la búsqueda de su propio desarrollo, en un período en el que, según palabras de Pérez Arroyo, "la evolución de los instrumentos musicales es paralela a la de la música que tienen que tocar" ${ }^{23}$.

\section{Los Instrumentos}

De los instrumentos anteriormente mencionados, en la documentación catedralicia cordobesa se alude casi siempre a dos: chirimía y sacabuche ${ }^{24}$. Ambos instrumentos, como también la bombarda y la flauta, son elementos típicamente bajomedievales. De uso generalizado en Castilla desde el siglo XIV, la chirimía fue el más popular de todos ellos, hasta el punto de ser considerados como sinónimos las acepciones de ministril y chirimía. Estos músicos gozaron de gran prestigio en la corte altoaragonesa, especialmente durante el reinado de Juan I

20. En 1569 se prohíbe expresamente a Medrano el Viejo que taña la corneta. Cfr. A.C.C. Actas Capitulares 1568-72. Libro 20, fol. 57v.․ Actas Capitulares 1572-77. Libro 22, fols. 30v. ${ }^{0}-31$.

21. GÓMEZ MUNTANÉ, C.: La música en la Casa Real altoaragonesa. 1979, pp. 25-28. La autora señala que los ministriles podían clasificarse en dos grupos: ministriles altos, que son los de viento y percusión, y ministriles bajos, que serían los de cuerda y tecla. Sin embargo, Sebastián de Covarrubias señala que no todos los instrumentos podían hacer las tres voces y cómo las chirimías no tenían registros bajos, encomendándose esa voz a los sacabuches. Cfr. la edición de Martín de Riquer, 1987, p. 436. Por lo general los instrumentos acompañaban a las voces, pero en otras ocasiones actuaban separadamente, pues con frecuencia la documentación alude a la asistencia de "los cantores" o "los ministriles" a determinadas festividades, en tanto que otras veces asisten conjuntamente.

22. Es ese el principal obstáculo que encuentra la organografía en nuestro país. Sobre el particular véase PÉREZ ARROYO, Rafael: "Los instrumentos musicales durante el período 1450-1600", en RUBIO, S.: Historia de la Música española... pp. 279-280. Una interesante serie de reproducciones de instrumentos del siglo XVI pueden verse en las láminas 666, 667, 668,669 y 683 de La Catedral de Sevilla. Sevilla, 1986.

23. PÉREZ ARROYO, Rafael: Op. cit., p. 279.

24. Sin embargo es posible que existiesen otros de los que apenas sabemos nada; sólo hemos hallado referencias a la cometa y al bajón, como alternativos de la chirimía, mencionados en un documento de 1574. A.C.C. Actas Capitulares 1572-77. Libro 22, fols. 30v-31. Por su parte, Sebastián de Covarrubias no recoge la acepción de "bajón", y de la "corneta" sólo indica que es instrumento que suena acompañado de los demás. Véase la edición de Martín de Riquer de 1987. 
para el que la chirimía era "el instrumento de sonido más agradable de todos cuantos existían" 25 .

Una de las más completas definiciones de este instrumento nos la proporciona Sebastián de Covarrubias, quien describe su estructura formal, manera de tocarla e incluso su timbre; de acuerdo con eso, la palabra chirimía procede del griego y con ella se designa al "instrumento de boca a modo de trompeta derecha sin vuelta, de ciertas maderas fuertes pero que se labran sin que tengan repelos porque en los agujeros que tiene se ocupan casi todos los dedos de ambas las manos... y es menester para tañer la chirimía manos y lengua y aún traer bragas justas por el peligro de quebrarse, como traían los tibicines antiguos y los pregoneros. Y así no es mal consejo para ministriles y aún para cantores el andar recogidos y abrigados. En la copla de los chirimías hay tiples, contraltos y tenores y los tiples no tienen llave para los puntos bajos; acomódanse con el sacabuche que tañe los contrabajos" ${ }^{26}$.

De la evolución de este instrumento clasificado, según Federico Sopeña, dentro de la familia de las dobles lengüetas, nacerá el oboe moderno ${ }^{27}$.

Por lo que respecta al sacabuche, designa en castellano al trombón de varas; para algunos la palabra puede derivar del término francés sacquebute "por la acción de meter y sacar el tubo metálico de cuya longitud depende el sonido que se obtenga" ${ }^{28}$. Covarrubias, por su parte, no señala su raíz etimológica y lo define como "instrumento de metal que se alarga y recoge en sí mismo; táñese con los demás instrumentos de chirimías, cornetas y flautas. Díjose así porque cualquiera que no estuviese advertido le parecería cuando se alarga, sacarle del buche" ${ }^{29}$. Este instrumento gozó de gran aprecio entre los compositores polifónicos, debido a su capacidad para la creación de muy diversos sonidos, según se alargase o contrajese ${ }^{30}$.

Ya se han señalado más arriba las dificultades que encuentra la organografía a causa de los pocos instrumentos originales que han llegado a nuestros días y cómo las artes plásticas pueden colaborar de modo decisivo en esa tarea. En el interesante trabajo publicado en 1972 por el P. Federico Sopeña aparecen repre-

\footnotetext{
25. GÓMEZ MUNTANÉ, C.: Op. cit., pp. 31-34.

26. COVARRUBIAS, Sebastián de: Tesoro de la Lengua Castellana. Edición de Martín de Riquer, Barcelona, 1987, p. 436. Una definición más breve en BARCIA, Roque: Primer diccionario etimológico de la lengua española. Madrid, 1880, tomo I, p. 1.189.

27. SOPEÑA, Federico: La música en el Museo del Prado. Madrid, 1972, p. 30. Los chirimías admitidos en 1563 en la capilla cordobesa respondían a las tres voces de tiple, contralto y tenor. Véase Actas Capitulares de 1562-64. Cuadernillo final sin foliar.

28. SALAZAR, A.: La música en Cervantes... p. 160.

29. COVARRUBIAS, S. de: Op. cit., p. 918.

30. SOPEÑA, F.: Op. cit., p. 104. Para el citado autor, el sacabuche consta de "dos tubos paralelos separados por un puente. Un tercer tubo en forma de U (la vara) conecta los dos tubos anteriores, dejando una parte de ellos libre y encajada".
} 
sentaciones de estos instrumentos, especialmente en obras flamencas, que permiten no sólo un acercamiento a su apariencia formal sino también el que podamos hacernos siquiera una idea aproximada de cómo y dónde se usaban y quiénes eran los que los manejaban. Porque estos instrumentos están a veces utilizados con sentido claramente alegórico, pero en otros casos lo están por su propia función, lo cual refuerza aún más el valor documental de estas obras ${ }^{31}$.

Pero acaso sean todavía más ilustrativas de lo que decimos las escenas en relieve que adornan las caras del facistol de la Catedral de Sevilla, labradas entre 1564 y 1566 según diseños del escultor Juan Bautista Vázquez el Viejo, en las que se representaron motivos relacionados con la música. Entre estos nos llama la atención la escena en que se muestra en plena actividad la capilla de ministriles de la catedral. Dejando a un lado la extraordinaria calidad estética de la pieza, la representación que comentamos nos proporciona una serie de datos que nos parecen de gran interés para el propósito que perseguimos. Así, lo primero que debe resaltarse es que aparecen los instrumentos, dos sacabuches y tres chirimías -es decir, el mismo número de instrumentos que formaba la capilla cordobesa-, y que su estructura concuerda cabalmente con las descripciones literarias conocidas. En segundo lugar, corrobora el aserto de que tales instrumentistas era seglares, a diferencia de los otros miembros de la capilla, que por lo general eran clérigos.

$\mathrm{Y}$ en tercer lugar, nos ilustra acerca de los modos y usos de la indumentaria de la época, que sería la habitualmente empleada por los hidalgos y artistas. Gracias a los excelentes estudios de Carmen Bernis podemos apuntar cuál sería el atuendo normal de un ministril: botas o zapatos acuchillados, medias de seda, calzas de muslos redondeadas y acuchilladas, jubón, ropilla y capa con capillas cerradas; la cabeza, tocada con gorra de copa algo elevada en la parte delantera ${ }^{32}$. Sin embargo, el cabildo cordobés era de la opinión de que no estuviesen tocados en el interior del templo y que guardasen durante sus actuaciones la debida compostura. Complemento del vestuario solían ser además las armas, por lo común espadas o dagas cortas ${ }^{33}$.

31. A título de ejemplo, véanse en SOPEÑA, F.: Op. cit., "La procesión de Ntra. Sra. du Sablon", de Denis van Alsloot (1570-1626), pp. 155-156, o el anónimo "Cristo Triunfante", p. 41.

32. Un estudio detallado de cada una de las piezas en BERNIS, C.: La moda en la España de Felipe II a través del retrato de Corte. "Alonso Sánchez Coello y el retrato en la corte de Felipe Il". Madrid, 1990, pp. 65 y ss.

33. A.C.C. Actas Capitulares 1572-73. Libro 21, fol. 56. IBIDEM, fols. 57v-58. 


\section{El Concurso}

Según la documentación consultada, a las plazas de ministriles de la Catedral de Córdoba se presentaron al menos tres grupos de instrumentistas: uno comandado por Carlos Cordella, otro por Juan de Arroyo, y el tercero por Luis de Medrano ${ }^{34}$.

Los únicos datos que hasta el momento conocemos con respecto al primero de estos grupos es que eran músicos de procedencia extranjera y que disponían de escasos recursos económicos, pero se ignora cuál fuera su lugar de origen, cuántos componentes lo integraban y qué instrumentos manejaban ${ }^{35}$.

El grupo de Juan de Arroyo estaba formado por instrumentistas locales y era el que hasta esa fecha había desempeñado el trabajo en la catedral ${ }^{36}$. Además de Arroyo figuraban en el equipo Antonio Rodríguez, sacabuche, Juan de Arellano y Gaspar González, de los que no sabemos el instrumento que tañían, si bien cabe en lo posible que fueran chirimías. En nuestra opinión, dos de estos músicos, Juan de Arellano y Juan de Arroyo, son los mismos que poco después aparecen integrando la Capilla Musical de la Catedral de Granada, que por entonces también crea una plantilla fija de instrumentistas ${ }^{37}$.

Es probable que ya hubiese en los ánimos de los cabildantes cierta predisposición favorable a Medrano, que se vería sin duda refrendada por su calidad. El tesorero del Cabildo y el canónigo Damián de Armenta habían hecho de él encendidos elogios ante el Obispo, sugiriendo que su contratación proporcionaría honra y prestigio a la música catedralicia "atento a ser como es tan buena pieza y tan hábil en su oficio..." 38 .

La valía profesional de Luis de Medrano debía ser conocida incluso fuera de Sevilla, como lo prueba la creación ex profeso para él de una plaza de chirimía y

34. Ya desde época medieval era frecuente que los ministriles formaran grupos de varios instrumentos que se complementaban entre sí, actuando por lo común uno de ellos como solista y los demás de acompañamiento. Véase al respecto GÓMEZ MUNTANÉ, C.: La música... pp. 31-34.

35. Por lo que se refiere al personaje que actúa como jefe de grupo, no puede precisarse bien si su apellido es CORDELLA o CORDELIS, dado que con ambas grafías lo hemos visto en las Actas catedralicias. A.C.C. Actas Capitulares 1562-64. Libro 18, fols. 112v-113: Petición de ayuda presentada por Cordella y sus compañeros ante el Cabildo el día 22 de junio de 1563 para poder emprender viaje de regreso a su tierra.

36. A.C.C. Actas Capitulares 1562-64. Libro 18, fol. 118. Los nombres de los componentes vienen reseñados al final de este mismo libro. Creemos que es el mismo grupo que en dos ocasiones - 1559 y 1561 - es enviado por el Cabildo a Lucena para tocar en los esponsales de la hija del Marqués de Comares. Cfr. Actas de 1558-60. Libro 16 s/f. y 1560-62. Libro 17, fol. 61v.

37. MARTÍN MORENO, A.: Historia... p. 153. Se menciona además otro nombre, Antonio Rodríguez, que también figura en Córdoba, pero de éste no podemos asegurar que sea el mismo, ya que su nombre seguirá apareciendo en los documentos cordobeses todavía durante algunos años más, si bien puede que marchase a Granada en fecha más tardía.

38. A.C.C. Actas Capitulares 1562-1564. Libro 18, fol. 114v. En esa misma sesión de Cabildo, celebrada el 28 de junio de 1563, se acordó aumentar el sueldo fijado para los ministriles, probablemente con idea de asegurarse su permanencia. 
el aumento de la cantidad previamente establecida como salario, como ahora veremos. Pero puede que hubiese otras razones; tal como se dijo al principio, don Cristóbal de Rojas había sido capellán del emperador Carlos y éste había sido un decidido admirador del músico sevillano Francisco Guerrero, quien, según veremos, fue el maestro de Luis de Medrano. Esta circunstancia pudo muy bien influir favorablemente en la elección del grupo sevillano, despertando el interés del prelado ya familiarizado con el tipo de música que estos ejecutaban.

El 16 de junio de 1563 fue sometido a examen el grupo de Juan de Arroyo, y tres días más tarde el de Luis de Medrano. La votación oficial tuvo lugar el 3 de julio, obteniendo Arroyo sólo dos votos, en tanto que Medrano lograba veinticinco, lo que le daba de modo automático el puesto; los demás componentes eran Alonso de Calzada, Jerónimo de Medina y Bartolomé Jiménez ${ }^{39}$.

\section{La Familia Medrano}

Llegados a este punto se hace necesario que planteemos algunas cuestiones, siendo quizá la primera el saber quién fue Luis de Medrano. No abundan los datos acerca de este personaje; las primeras referencias a su persona actualmente conocidas son las que publicara en 1954 Robert Stevenson; según los documentos por él transcritos, en 1538 Luis de Medrano es de nuevo admitido en la Capilla de ministriles de la Catedral de Sevilla, de la que ya formaba parte, pero que había decidido abandonar para marchar a las Indias. Y como tal figura en la relación de músicos catedralicios que estaban a las órdenes de Francisco Guerrero, publicada por Lloréns Cisteró en 1985, donde se hace hincapié en su faceta de hombre de carácter difícil, propenso a buscarse líos ${ }^{40}$. Pero desde el comienzo queda patente su valía profesional; efectivamente, el Cabildo hispalense prefirió olvidar su falta de disciplina y el desacato a su autoridad, al considerar más importante su reintegración al trabajo, estimándolo "muy necesario para el servicio de esta Iglesia y que su ausencia hace muy gran falta a la capilla de ministriles". A partir de ese momento su presencia en los documentos está siempre relacionada con peticiones de aumento de sueldo, que en 1546 es de 20.000 maravedíes y dos cahíces de trigo, y en 1556 es ya de 30.000, con idéntica cantidad de grano. Se le menciona por última vez el 12 de julio de 1563, cuando,

\footnotetext{
39. A.C.C. Actas Capitulares 1562-64. Libro 18, fol. 118. El salario global del grupo quedó fijado en 200 ducados y 10 cahíces de trigo.

40. STEVENSON, Robert: La música en la Catedral de Sevilla. Documentos para su estudio Sociedad Española de Musicología. Madrid, 1985, pp. 33 y ss. En el documento de 1538 se hace constar que Medrano se había ido a Sanlúcar sin permiso para embarcarse a Indias. LLORÉNS CISTERÓ, J. M.: Música y músicos en la Sevilla del Siglo de Oro. B.B.A. Segunda Epoca. N. XIII. Sevilla, 1985, p. 124.
} 
con el beneplácito del Cabildo hispalense, abandona la ciudad para establecerse en Córdoba, donde permanecerá ya hasta su muerte ${ }^{41}$.

La investigación documental en el archivo catedralicio de Córdoba nos ha permitido ampliar los datos sobre este curioso personaje. En primer lugar hay que señalar que existieron dos personas con el mismo nombre, padre e hijo, y los dos fueron ministriles en la Catedral de Córdoba, en cuya documentación aparecen diferenciados con los calificativos de "Luis de Medrano el Viejo" y "Luis de Medrano el Mozo". Aunque el músico más reconocido era Medrano el Viejo, realmente el que opositó a la Capilla de Córdoba fue el joven Luis, quien por entonces no había cumplido todavía los catorce años. Según se indicó más arriba, la plaza de Medrano el Viejo se debió a una decisión posterior conjunta de prelado y cabildo quienes, reunidos capitularmente "de conformidad, nemine discrepante", acordaron crear una plaza nueva y separada de las otras, con carácter vitalicio, destinada a éste, dotándola con 45.000 maravedíes y cuatro cahíces de trigo de asignación anual. Esta plaza se amortizaría automáticamente a la muerte de su titular "porque no es de las contenidas en el estatuto" ${ }^{42}$.

Resulta, pues, más que probable que sus servicios en la catedral hispalense, y en especial su formación junto a Guerrero, al que se tenía por extraordinario maestro "que sabía enseñar música mejor que nadie, tanto la teoría como la práctica", fueran razones con peso suficiente para inclinar la balanza a su favor. La capacidad docente de Luis de Medrano queda plenamente corroborada algunos años después cuando el Cabildo dispone que "dos días en semana los ministriles se junten en casa de Luis de Medrano el Viejo a estudiar y pasar ( sic) lo que han de tañer en el coro y estos días sean los que el dicho Medrano señalare..." 43 .

Pero las relaciones de Medrano con el maestro Guerrero no fueron simplemente laborales, sino que entre ellos debió haber también amistad. Al menos así parece probarlo el hecho de que en marzo de 1566, Medrano actúe como intermediario del músico sevillano, ofreciendo al Cabildo de Córdoba para su posible compra "un libro de música de nueve misas y tres motetes de Francisco Guerrero, maestro de capilla de la iglesia de Sevilla". Un mes más tarde se formalizará

41. STEVENSON, R.: La música... Pp. 33, 35 y 50. Por su parte, el Cabildo de Córdoba le subvencionó con 20 ducados para que pudiese afrontar los gastos del traslado de casa y familia. A.C.C. Actas Capitulares 1562-64. Libro 18, fol. 119. Asimismo, gracias a las investigaciones de Stevenson, sabemos que Medrano tuvo un hermano también músico, que estuvo a punto de ingresar en la capilla sevillana, aunque se desconocen su nombre y el instrumento que tañía; pero finalmente el puesto lo ocupó un ministril murciano. Cfr. op. cit., p. 42.

42. A.C.C. Actas Capitulares 1562-64. Libro 18, fols. 118 y v.

43. ZAYAS, Rodrigo de: La Catedral de Sevilla y la didáctica musical evangelizadora en Nueva España, en tiempos de Juan de Mesa. B.B.A. Segunda Epoca. N. XII. Sevilla, 1984, p. 152. A.C.C. Actas Capitulares 1568-72. Libro 20, fol. 34v. 
la compra del libro, fijándose su valor en siete ducados ${ }^{44}$. este dato nos parece digno de interés por cuanto plantea algunos aspectos nuevos con relación al gran músico sevillano. Según han señalado algunos autores, en 1556 Francisco Guerrero había viajado a Portugal para ofrecer su primer libro de misas - que había sido editado en París- al rey Juan III; posteriormente llevó algunas composiciones a Toledo, y en 1561 se publicará en Lovaina su Magnificat ${ }^{45}$. De todo ello pueden colegirse dos posibilidades: que el libro traído por Medrano a Córdoba es el mismo que había sido llevado a Portugal, o que nos encontramos ante un nuevo texto de música sacra del maestro, en el que acaso aparecieran primeras versiones de los Motetes que luego publicara en 1570 en Venecia ${ }^{46}$.

Pero además la existencia del libro nos lleva a otro tema: los textos musicales para instrumentos. Generalmente se admite la idea de que no debió existir música escrita ex profeso para ministriles, ya que estos se ajustaban a la música polifónico-vocal que los cantores ejecutaban en el oficio de la misa, si bien y en la medida en que su virtuosismo se lo permitiese, podían introducir variaciones en la misma ${ }^{47}$. Sin embargo, el músico portugués André de Escobar había escrito un método de aprendizaje de la chirimía, lo cual sugiere que pudo haber otros de la misma índole y que esto no sería en absoluto un caso excepcional ${ }^{48}$. Así pues, la compra del libro de Misas y Motetes de Francisco Guerrero serviría tanto para los cantores, cuanto para "lucimiento" de ministriles, habituados ya al tipo de música que el maestro componía.

Entre los días 3 y 5 de julio de 1563 Luis de Medrano el Viejo, en nombre propio y en el de su hijo que aún era menor de edad, firmará su compromiso de servir a la Catedral durante al menos una década; en caso de incumplimiento, les sería impuesta una multa de 300 ducados y el grupo de ministriles que había sido admitido con ellos perdería automáticamente su plaza ${ }^{49}$.

La formación musical del viejo Medrano tuvo su correcta prolongación en su hijo, quien a pesar de ser casi un niño, supo demostrar ante el cabildo cordobés "su habilidad y suficiencia" en el manejo de los instrumentos, consiguiendo no

\footnotetext{
44. El Cabildo recaba del Maestro de Capilla -por entonces lo era Andrés de Villalar- información acerca del citado libro. A.C.C. Actas Capitulares 1565-68. Libro 19, fol. 47. Es de suponer que Luis de Medrano no habría facilitado la compra de este libro de no ser su autor alguien bien considerado por él. El 2 de abril de 1566 se autoriza la compra del libro, Ibidem, folio 51 .

45. REESE, Gustave: La música del Renacimiento. 2. Madrid, 1988, p. 691. Sin embargo A. Martín Moreno indica que este hecho se produjo en 1566. Cfr. Historia de la muisica... p. 134. Véase también RUBIO, S.: Historia... p. 169.

46. Hasta el momento no hemos podido comprobar si el citado libro se conserva entre los fondos musicales de la catedral, lo cual ayudaría sin duda a despejar las incógnitas planteadas.

47. RUBIO, S.: Historia... p. 47.

48. REESE, G.: La música... p. 695

49. Esta cláusula carecía de validez en el caso de que le sobreviniese la muerte a Medrano. A.C.C. Actas Capitulares 1562-64. Libro 18 , fols. 119 y 121 y v.
} 
sólo un puesto de ministril sino además una gratificación anual vitalicia de 6.500 maravedies, lo cual habla por sí solo de su valía profesional ${ }^{50}$. No parece probable que el pequeño Medrano recibiese enseñanzas directas del propio Guerrero, pero no hay duda de que bien pudo haberle visto tañer y, desde luego, aprendería con su padre, no sólo a tocar chirimía, sino también los otros instrumentos de viento comunes a los ministriles, según veremos en su momento.

La elección de Luis de Medrano y su grupo no estuvo exenta de problemas; algunos capitulares mostraron su desacuerdo con la elección de Medrano y sobre todo con que se le aumentase el sueldo, aduciendo que así se engañaba a todos los demás ministriles que hubieran quizá optado al puesto de haber sido más alto el salario ${ }^{51}$. Pero los problemas más graves se van a producir entre los propios componentes de la Capilla. Con Medrano habían concursado otros tres músicos que formaban un grupo homogéneo, pero el Cabildo optó por introducir en él un instrumentista más, que no fue bien recibido, sobre todo por Medrano, a quien desagradó profundamente lo sucedido ${ }^{52}$. Por ese motivo se apresurará a protestar ante el Cabildo argumentando "que él no puede tener ni sufrir en su compañía a Antonio Rodríguez sacabuche", por lo cual solicita su destitución o en su defecto, que le rescindan a él el contrato y le permitan volverse a Sevilla; finalmente todo se solucionará gracias a los buenos oficios del provisor don Gonzalo Melén$\operatorname{dez}^{53}$.

Esto no fue sino una pequeña muestra de lo que iba a ser casi la norma. Las disputas entre los ministriles fueron constantes, casi siempre motivadas por problemas financieros, al tiempo que son frecuentes las amonestaciones del Cabildo a causa de las deficiencias en el trabajo. Como muestra puede señalarse la penalización impuesta a Medrano el Joven en 1569 por sus reiteradas desobedien$\operatorname{cias}^{54}$.

La documentación manejada refleja con claridad la superior consideración de Medrano frente a los demás ministriles, lo que evidentemente no debió granjearle simpatías entre sus colegas; es posible que no le agradase que le impusieran personas ajenas a su grupo, prefiriendo trabajar junto a instrumentistas conocidos

50. A.C.C. Actas Capitulares 1562-64. Libro 18, fol. $118 \mathrm{v}$

51. A.C.C. Actas Capitulares 1562-64. Libro 18, fols. 120v-121.

52. Se trataba de un sacabuche llamado Antonio Rodríguez, cuyo salario se pagaría entre el cabildo catedralicio y el cabildo de la ciudad, que de este modo se reservaba el derecho de poder emplear a los ministriles en las fiestas y celebraciones ciudadanas. Véase Actas Capitulares 1562-64. Libro 18, fols. 118v-119.

53. Lógicamente, tampoco Rodríguez quería estar con Medrano; Véanse A.C.C. Actas Capitulares $1562-64$. Libro 18 , fols. $119 \mathrm{v}-120,120 \mathrm{v}$ y $122 \mathrm{v}$ respectivamente. Es posible que la enemistad entre ambos músicos estuviere motivada por el hecho de pertenecer Rodríguez al grupo desbancado por Medrano en el concurso, lo que explicaría el enfrentamiento.

54. A.C.C. Actas Capitulares 1568-72. Libro 20, fol, $68 \mathrm{v}^{2}$. Sin embargo, esta situación parece que fue habitual entre los miembros de este colectivo, pues este tipo de altercados se recoge también en otras catedrales españolas. Véase al respecto, RUBIO, S.: Historia... p. 46. 
y formados junto a él. Tres meses después de constituirse la Capilla Musical, por razones no bien precisadas, uno de los sacabuches presentó al cabildo su renuncia a la plaza; se comisiona entonces a Luis de Medrano para que "haga llamar a Pizarro de Sevilla y que venga para que los dichos señores vean si conviene proveerlo con los quince mil maravedíes de la ciudad y lo demás de la fábrica". Pizarro no debió responder al requerimiento y, en consecuencia, la plaza seguía vacante un mes después; llega entonces al Cabildo un joven sacabuche de Baeza llamado Juan Alvarez solicitando el puesto, por lo que se designa a tres capitulares para que "lo vean tañer y vean su habilidad"; la decisión fue favorable, y se le admitió con sueldo de cincuenta ducados y dos cahíces de trigo ${ }^{55}$.

La llegada del joven baezano no gustó tampoco a nuestro músico, que procuró por todos los medios a su alcance hacerle desistir de su empleo. Juan Alvarez se quejará reiteradamente ante los capitulares del comportamiento de Medrano, quien a la postre será el que salga ganando ${ }^{56}$. Con todo, sus mayores altercados fueron con el sacabuche Antonio Rodríguez, y el Cabildo luchará en vano para evitarlos y conseguir que Rodríguez continuase a su servicio. El enfrentamiento terminará afectando a todos los demás músicos, ya excesivamente molestos por las continuas acusaciones que Antonio Rodríguez hacía al Cabildo acerca de ellos, centradas básicamente en la idea de que no le hacían partícipe de las ganancias. A raíz de una de estas denuncias, los ministriles - que a la sazón eran Medrano el Mozo, Bartolomé Jiménez, Alonso de Calzada y Juan Alvarez-, presentaron al Cabildo el 7 de julio de 1568 un escrito en el que protestaban la decisión capitular de obligarles a compartir ganancias con Antonio Rodríguez como si estuviese enfermo, siendo así "que el dicho Antonio Rodríguez no estaba enfermo, pues fuera de la iglesia se iba a tañer donde por su interés le parecía". Eso llevó a Rodríguez a presentar un informe avalado por el doctor Estrada en el que se hacía constar que había estado "tan enfermo que estaba a peligro de la vida y que le haría notable daño tañer el sacabuche y usar de su oficio" 57 .

Sin embargo los ministriles, suponemos que alentados por Medrano el Viejo, no se mostraban dispuestos a ceder, por lo que desacatan lo ordenado por el Cabildo de tal modo que en sesión de 4 de agosto de 1568 se les manda cumplir

55. A.C.C. Actas Capitulares 1562-64. Libro 18, fol. 146v. Pizarro había venido a examinarse cuando Medrano, pero no se sabe por qué no fue aceptado. Véase Actas 1562-64. Libro 18, cuademillo final sin paginar. IBIDEM, fols. 153v-154. Con todo, el rechazo de Juan Alvarez no debió pasar a mayores por cuanto éste permanecerá durante bastantes años al servicio del cabildo cordobés, bajo la dirección del propio Medrano.

56. A.C.C. Actas Capitulares 1565-68. Libro 19, fols. 13v y 100. Con fecha 4 de febrero de 1567 se establece que siempre que Luis de Medrano actúe en fiestas de cualquier tipo ha de llevar a todos los músicos, e incluso contar con los que estuvieran enfermos, recibiendo como contrapartida doble cantidad de dinero que los demás. Véase IBIDEM, fol. 104.

57. A.C.C. Actas Capitulares 1565-68. Libro 19, fols. 157 y $158 \mathrm{v}-159$. 
lo acordado y se les prohíbe la asistencia "a fiestas ningunas en Córdoba ni fuera de ella... y que si quieren litigar que el pleito se siga a costa de los excusados". Ni que decir tiene que hasta aquí llegaron las cosas, porque la amenaza económica era demasiado seria para no ser tenida en cuenta ${ }^{58}$.

\section{Las Actuaciones fuera de la Catedral}

Tal como se ha indicado más arriba, con cierta frecuencia encontramos pruebas documentales de las actuaciones de la Capilla Musical catedralicia fuera de los muros de ésta. En efecto, tanto los cantores como los instrumentistas eran requeridos para intervenir no sólo en ceremonias religiosas sino también en fiestas profanas; este hecho era frecuente entre estos profesionales, dado su escaso número y la carencia de escuelas musicales fuera del ámbito religioso que hubieran favorecido la difusión de la práctica musical. Por otro lado, hay que tener en cuenta que no debía resultar rentable el mantenimiento de una de estas agrupaciones con carácter exclusivo si no se era noble o de la casa real.

Precisamente la escasez de instrumentistas y el tener que prodigar su presencia en sitios muy dispares fueron, en opinión de Samuel Rubio, dos de los principales motivos de sus continuas quejas económicas, que les llevan a pedir constantemente ayuda financiera, e incluso los considera razones suficientes para justificar su nomadismo, pues irán de una ciudad a otra buscando las mejores perspectivas laborales, que no siempre se revelarán reales y efectivas ${ }^{59}$.

Los ministriles y cantores cordobeses actuaron desde su constitución en numerosos lugares, tanto dentro de la ciudad como fuera de ella. Era frecuente que solicitaran su presencia en fiestas patronales, procesiones, celebraciones gremiales, novenas, rogativas, profesiones de religiosas, etc. Estas actuaciones no se limitaban a interpretaciones de música sacra, sino que también actuaban en festejos de carácter profano, tales como esponsales, fiestas de toros y en general en cualquier celebración popular que organizara el Cabildo de la Ciudad, las corporaciones gremiales e incluso los propios vecinos. Sirvan de ejemplo a cuanto decimos la asistencia a las fiestas organizadas por los escribanos en honor de Nuestra Señora de la Concepción (1564 y 1566), a las de San Francisco en la Casa Grande de San Francisco (1567 y 1568), a la profesión de una religiosa en el convento de Santa Clara (1568), al traslado de la Virgen de Villaviciosa de 1572, o a las fiestas de Nuestra Señora de las Nieves en el Monasterio de Regina

58. A.C.C. Actas Capitulares 1565-68. Libro 19, fol. 168-169.

59. RUBIO, S.: Historia... pp. 43-48. El propio Medrano el Joven intentó abandonar Córdoba, para integrarse en la Capilla del duque de Medina, por lo que el Cabildo decidió despedirlo, sin embargo esa situación no debió culminarse por cuanto Medrano siguió al servicio catedralicio. A.C.C. Actas Capitulares 1568-72. Libro 20, fol. 92. 
(1574). En cuanto a celebraciones profanas, mencionaremos las Fiestas de Toros celebradas en 1566 en la Corredera y las organizadas en Ecija en septiembre de ese mismo año, con motivo del feliz parto de la reina ${ }^{60}$.

En correspondencia, el Cabildo de la ciudad contribuía financiando parte del salario de uno de los integrantes de la Capilla; así mismo es de suponer que recibirían algún tipo de estipendio por estas actuaciones, pero no sabemos con certeza ni la cantidad ni cómo se hacía el reparto.

Por lo general el Cabildo catedralicio accedía a tales peticiones, siempre que contaran además con la aquiescencia del Obispo -o en su lugar del Provisor- y que la asistencia a tales celebraciones no fuera nunca en detrimento del culto catedralicio, ni supusiera afrenta o escándalo para el Cabildo ${ }^{61}$. No siempre se deslizarán las cosas por este terreno armónico, surgiendo con facilidad las ocasiones en que estas reglas no se respetaban. En 1574 se plantea la posibilidad de que sea el Cabildo el que sufrague íntegramente los gastos de la Capilla, con lo que se evitarían, al menos, dos cosas: que los músicos se vieran forzados a actuar en lugares poco dignos que desdijeran de su cometido sacro y, sobre todo, que surgieran impedimentos a la hora de cobrar el salario que les correspondía, hecho éste bastante frecuente ${ }^{62}$.

\section{La capilla musical después de don Cristóbal de Rojas}

En 1571 el obispo de Córdoba fue promovido a la sede hispalense, nombrándose para sucederle en Córdoba al franciscano fray Bernardo de Fresneda, antiguo confesor de Felipe II, que llegará a su nueva sede en diciembre de $1572{ }^{63}$.

Durante el tiempo en que la sede estuvo vacante las relaciones entre los ministriles volvieron a ser insostenibles y el desacato para con el maestro de Capilla era ya generalizado. Esto obligará al Provisor y al Cabildo a reunirse el 22 de octubre de 1572 con el fin de intentar restablecer la perdida disciplina y de fijar una serie de normas, más estrictas que las hasta entonces vigentes, que además sirvieran para mejorar la calidad musical del grupo, por entonces considerablemente mermada. Como primera medida se impuso a los ministriles la

60. A.C.C. Actas Capitulares 1562-64. Libro 18, fol. 232. 1566, diciembre 11. Actas Capitulares 1565-68. Libro 19, fols. 96v., 90, 186 y 192. 1572, septiembre 20. Actas Capitulares 1572-73. Libro 21, fol. 33v. Actas Capitulares 1572-77. Libro 22, fol. 43. 1566, junio 22. Actas Capitulares 1565-68. Libro 19, fol. 66. 1566, septiembre 25. Actas Capitulares 1565-68. Libro 19, fol. 89v.

61. A.C.C. Actas Capitulares 1565-68. Libro 19, fol. 63v.

62. A.C.C. Actas Capitulares 1572-77. Libro 22, fols. 77v-78, y fol. 78v. Al aumentar la Iglesia la asignación a los ministriles quedaba resuelto el problema del salario del sacabuche Juan de Segovia, que era el que entonces se financiaba con el dinero de la ciudad. Actas Capitulares 1572-73. Libro 21, fol. 158.

63. Para el nuevo Obispo, véase GÓMEZ BRAVO, J.: Catálogo... T. II, pp. 486 y ss. 
obligación de ensayar dos veces a la semana -martes y viernes- durante una hora "por la tarde en verano de cuatro a cinco y en invierno de tres a cuatro", utilizando para tales ensayos "la cámara que está encima de la Capilla de los Recaudos" 64 .

Como responsable de todo se designa a Luis de Medrano el Viejo, a quien se hace entrega de la llave de la cámara (pues allí debían guardarse los instrumentos y los papeles de música) y se le encomienda el gobierno y dirección de todo el grupo, responsabilidad que suponía, no sólo la elección de la música que habría de interpretarse en cada momento, sino también quién habría de hacerlo: “... y en cuanto a la música, lo que él señalare y voz que a cada uno de los músicos dijere, sea obligado a la tañer y cumplir porque para este ejercicio y todo lo demás tocante a la música el Señor Provisor y los señores Deán y Cabildo le dan la mayoría y gobierno de ella..."; el incumplimiento de lo anterior se castigaría con multas de real y medio por falta. Asimismo se les exhorta a la reconciliación, con amenaza de despido si persistían las riñas y desavenencias entre ellos.

La situación mejoró por un tiempo, pero paulatinamente volverán a incurrir en idénticas faltas -sobre todo en lo concerniente a la asistencia-; eso originará que el Cabildo acuerde en 1574 aumentar considerablemente las sanciones económicas, remedio que se revela otra vez inoperante. En 1576 se optó por individualizar la sanción, haciéndola proporcional al salario de cada músico ${ }^{65}$. Por paradójico que pueda parecer, estas amonestaciones del Cabildo no serán obstáculo para que frecuentemente los ministriles soliciten ayudas económicas, ya para alimentos ya para vestuario, que por lo general les eran concedidas ${ }^{66}$.

\section{La muerte de Luis de Medrano}

Las continuas tensiones internas y el esfuerzo físico que se precisaba para tañer bien la chirimía propiciaron que ambos Medrano acusaran problemas de salud, que en el caso del padre acabarán por llevarle a la muerte. En 1573

\footnotetext{
64. A.C.C. Actas Capitulares'1572-73. Libro 21, fols. 54-56. Si los días establecidos para ensayo coincidían con alguna festividad, se debía trasladar aquél al día siguiente.

65. 20 de agosto de 1574: Normas para los ministriles. A.C.C. Actas Capitulares 1572-77. Libro 22, fols. 49v$52 v$. Se establece como pena la pérdida del salario correspondiente a ese día, que sería doble si se trataba de una festividad solemne. Se consideraban solemnes doce: Pascua de Natividad incluyendo los maitines, Primer día de Pascua de Resurrección, primer día de Pascua de Espíritu Santo, Epifanía, Corpus Christi, Purificación, Asunción, S. Pedro y San Pablo, Todos los Santos, Domingo de Ramos, Viernes Santo y los tres días de tinieblas. 27 de julio de 1576: se acuerda que la pena por faltas se establezca proporcionalmente al salario. IBIDEM. Fols. 228v-229.

66. Curiosamente en muchos casos se indica que se le concede al interesado por sus buenos servicios, lo que inclina a pensar que la situación no sería tan grave como parece desprenderse de la lectura documental, tratándose más bien de un medio para tener controlado al grupo como colectivo. Como muestra véase Actas Capitulares 157277. Libro 22 , fols. $74 v$ y $76 v$.
} 
Medrano hijo solicita del Cabildo ayuda económica porque está enfermo, por lo que se le dan seis ducados y ocho pares de gallinas. No conocemos la naturaleza de la enfermedad, sólo que fue larga y revistió cierta gravedad, hasta el punto de que por segunda vez hubo de pedir ayuda a los cabildantes quienes, "atento a su pobreza y enfermedad larga" le conceden cien reales, es decir, 3.400 maravedíes. No terminarán aquí los males del ministril, quien de nuevo en 1574 es presa de enfermedad hasta el grado de no poder tañer chirimía ${ }^{67}$.

Por los mismos días, el viejo Medrano se resiente también de salud, por lo que se acuerda eximirle temporalmente de sus obligaciones de modo "que hasta fin de agosto de este año pueda venir y dejar de venir a servir a su oficio, el cual tiempo le dan por recreación" ${ }^{68}$. En agosto de 1575 la situación parece estabilizada y el más joven de los Medrano obtiene autorización del Cabildo para ir a Jaén "a ver la Verónica por cuanto lo había prometido estando enfermo", para lo cual se le conceden ocho días de asueto ${ }^{69}$.

En agosto de 1576 se produjo la muerte de Luis de Medrano el Viejo, y su pérdida se deja sentir en todos aquellos que le conocían. El Cabildo cordobés, en prueba de gratitud por los servicios que había prestado, accede a la ayuda económica solicitada por su viuda entregándole cuatro ducados. Incluso el Prelado dejará constancia de su consideración hacia el desaparecido músico, haciendo saber a los capitulares que "sería contento que de la fábrica se le diese algo", deseo que se materializará en un nuevo donativo, esta vez de cien reales ${ }^{70}$.

Con la muerte del instrumentista sevillano se cierra la primera etapa de la Capilla Musical de la Catedral de Córdoba en los años del Renacimiento. Esta seguirá en activo, pero ya dentro de un contexto diferente, por cuanto a partir de este momento faltará la cabeza que hasta entonces la había regido y serán mucho más frecuentes los cambios entre sus componentes que, a juzgar por lo que conocemos, no gozan ya del prestigio y la formación profesional que fueron los principales rasgos que definieron el arte de Luis de Medrano.

67. A.C.C. Actas Capitulares. Libro 21, fols. 156v, 157 y 182v. El 3 de julio de 1573 se acuerda en Cabildo darle algunos días de asueto para que se recupere totalmente. Véase fol. $189 \mathrm{v}$. Medrano el Joven solicita del Cabildo la dispensa de tañer chirimía, ofreciendo a cambio que le dejen tocar cometa o bajón. Cfr. Actas Capitulares 1572-77. Libro 22, fols. 30v-31. Recuérdese que Sebastián de Covarrubias avisaba a los chirimías del riesgo de "quebraduras"; es posible que esa fuera la enfermedad padecida por Medrano.

68. A.C.C. Actas Capitulares 1572-77. Libro 22, fol. 191v. Se hace constar que este permiso es para el Viejo, de ahí que creamos que esas "vacaciones" debieron estar motivadas más por razones de edad que de enfermedad, siendo fruto de la casualidad la coincidencia con la enfermedad del hijo.

69. A.C.C. Actas Capitulares 1572-77. Libro 22, fols. 142 y 143. Dos años más tarde, en agosto de 1577 también pide permiso para ir a Jaén, "a su romería", el ministril Juan de Segovia. Véase Actas Capitulares 1577-79. Libro 23 sin foliar.

70. A.C.C. Actas Capitulares 1572-77. Libro 22, fols. 234 y 235. 